\title{
TURISMO, TERRITORIO Y MEDIO AMBIENTE EN MORELLA. DEL P.G.O.U. (1986) A LA AGENDA 21 LOCAL (2000)
}

\author{
Emilio M. Obiol Menero \\ Departamento de Geografía \\ Universidad de Valencia \\ Hernán Canós Beltrán \\ Departament d'Història, Geografia i Art \\ Universitat Jaume I (Castellón)
}

\section{RESUMEN}

El presente trabajo intenta analizar desde la perspectiva de la geografía del turismo, esto es atendiendo a las acciones territoriales y ambientales, de qué forma Morella ha ido configurándose como el destino turístico de interior más visitado del País Valenciano.

Desde 1964 hasta el año 2000, primero un conjunto de iniciativas públicas y privadas, ilustradas pero relativamente improvisadas, y desde 1980 tres documentos estratégicos de ordenación territorial (PGOU, 1986; PIRCT, 1996; PACA, 2000), han ido sentando las bases para que el turismo posibilite la recuperación activa del patrimonio cultural y dinamice el conjunto de la economía del municipio y de la comarca.

En ese contexto, la marca Morella, un producto turístico cultural consolidado, necesita pasar de las acciones cuantitativas de adecuación y puesta en valor turístico a otras cualitativas presididas por la sostenibilidad. Es hora de asumir el reto de la gestión sostenible del turismo, lo que requiere conciliar la conservación natural y cultural con las nuevas perspectivas económicas y sociales que abre la función turística.

Palabras clave: turismo, territorio, medio ambiente, sostenibilidad, urbanismo, revalorización patrimonial, Agenda 21.

\section{SUMMARY}

The present work tries to analyze from the perspective of the geography of the tourism, this is assisting to the territorial and environmental actions, of what Morella forms he/she has gone configuring you as the tourist destination of more visited interior of the Country Valencia.

From 1964 until the year 2000, first a group of public and private, cultured but relatively improvised initiatives, and from 1980 three strategic documents of territorial ordination (PGOU, 1986; PIRCT, 1996; PACA, 2000), they have gone sitting down the bases so that the 
tourism facilitates the active recovery of the cultural patrimony and energize the group of the municipal and regional economy.

In that context, the mark Morella, a consolidated cultural tourist product, he/she needs to pass of the quantitative actions of adaptation and setting in tourist value to other qualitative ones presided over by the sostenibilidad. It is hour of assuming the challenge of the sustainable administration of the tourism, what requires to reconcile the natural and cultural conservation with the new economic and social perspectives that he/she opens the tourist function.

Key words: Geography, tourism, territory, enviroment, sustainability, urbanism, spatial actions, cultural heritage.

\section{Introducción y planteamiento}

El principal objetivo de este trabajo será realizar un análisis geográfico de las acciones territoriales que, como causa o consecuencia del desarrollo turístico, ha emprendido Morella a lo largo de los últimos 36 años (1964-2000).

Nuestra hipótesis es que el municipio de Morella en este periodo de tiempo, primero sin ser consciente de ello, y después con una estrategia definida de desarrollo turístico integrado, ha implementado toda una serie de actuaciones en el ámbito geográfico que la han situado como uno de los destinos de interior más visitados no sólo del País Valenciano sino también de España. Morella, con 0,5 millones de visitantes/año (1998), presenta, por ejemplo, unos registros de frecuentación similares a los de Ávila o poco menos de la mitad de los de Salamanca, ciudades ambas Patrimonio Cultural de la Humanidad, galardón al que aspira ahora la capital de Els Ports.

El artículo presenta dos niveles de análisis turístico. En una primera parte, se abordan las actuaciones territorales estrictamente urbanas, después se tratan las cuestiones ambientales. Finalmente, y a modo de alternativas de actuación, se realizan unas macropropuestas.

En el fondo, lo que se pretende es analizar la estrategia de desarrollo local emprendida por Morella como ciudad cultural que quiere compaginar el hecho turístico y la habitabilidad. La población, sabedora del carácter no renovable de los recursos que la sustentan, persigue integrar el turismo en un marco de compatibilidad con el medio ambiente, con la sociedad, con el patrimonio cultural y con la economía, esto es con los principios de sostenibilidad.

\section{Evolución histórica del urbanismo de Morella. Una síntesis}

\subsection{Del Cuatrocientos a los años 1980}

Morella ha experimentado a través de su historia decisivas transformaciones que han convertido su medio natural en paisajes de cultura, dando resultado finalmente a un patrimonio territorial, simbolizado en la ciudad. Hoy, este patrimonio, impulsado por el turismo, trasciende su dimensión estrictamente cultural como legado histórico y se transforma en recurso productivo para el desarrollo.

El urbanismo medieval (siglos XIV-XVI), que hoy supone el verdadero hito turístico, es el que pone los fundamentos de la trama de la ciudad, es decir, del carácter irrepetible de Morella como ciudad histórica. Es entonces cuando se forjó la armonía entre topografía, roquedo y formas constructivas de la ciudad dando lugar a conjuntos indisociables de gran belleza. 
La Edad Moderna constituyó un periodo de transición en el que paralelamente a la consolidación (el Pla dels Estudis; ver Mapa 1) y densificación de la trama urbana, se asiste a reconstrucciones y alteraciones urbanas derivadas de epidemias, de la independencia de algunas de sus aldeas (Vilafranca) y de destrucciones ocasionadas por las guerras (G. de Sucesión).

La Edad Contemporánea se caracteriza por un notable crecimiento demográfico y socioeconómico. Las transformaciones urbanas se concretan en la apertura del tramo inferior de la actual Costa de Sant Joan, la urbanización de la Plaça de Colón, la construcción del edificio del Col.legi dels Escolapis así como con la construcción residencial y fabril extramuros, sobre todo en l'Hostal Nou, en la Fàbrica de Giner y en la cuesta de acceso a la Porta de Sant Mateu. Todas estas iniciativas fueron acompañadas de densificaciones intramuros y de ciertas mejoras en las infraestructuras, destacando la instalación del alumbrado público, a gas, y la construcción de un pequeño teatro (Gamundí, 1996).

El siglo XX representará ya la total ocupación de los espacios intramuros mediante un proceso de crecimiento desordenado y carente de dotación infraestructural en el que las viviendas conviven con edificios fabriles. Estas transformaciones hacen necesario un nuevo acceso rodado a la ciudad que se habilitó junto a la torre de la Font y que, por primera y única vez, rompe la continuidad del lienzo perimetral de muralla.

Si durante el primer cuarto de siglo, a pesar de algunos primeros síntomas de dificultades, se sigue manteniendo cierto ritmo de vida y de construcción gracias a las exportaciones favorecidas por la $1^{\text {a }}$ Guerra Mundial, el cierre en 1926 de la Fàbrica de Giner, principal motor económico de la comarca, supone el inicio de un periodo de languidecimiento y crisis.

Las dificultades socioeconómicas se agudizarán durante la Guerra Civil y la postguerra, y habrá que esperar a mediados de los años 60 para que, como en el resto de España, empiecen a sentarse las bases que propiciarán una nueva, incipiente, modesta y transcendental actividad económica, el turismo' ${ }^{1}$. De la mano del morellano Mosen Manuel Milián Boix, se inicia un lento proceso de estudio y recuperación del patrimonio, inspirado en el ejemplo de Italia, país al que este eclesiástico viaja a menudo, y en donde observa la trascendencia que puede adquirir la trilogía cultura-patrimonio-turismo. Milián y su entorno pronto vislumbraron que la recuperación del patrimonio como recurso susceptible de aprovechamiento turístico conformaba la gran oportunidad de futuro de la ciudad. Sin embargo, Morella y su comarca, Els Ports, siguen constituyendo un escenario alejado del turismo convencional. Únicamente algunos viajeros y excursionistas de las cercanas comarcas catalanas o de la ciudad de Valencia se aventuran a deambular por estas tierras ${ }^{2}$.

$\mathrm{El}$ «desarrollismo» turístico, significará ya una nueva etapa en las aspiraciones turísticas de la ciudad ${ }^{3}$. Los primeros flujos de turistas procedentes de las cercanas playas litorales (Penís-

1 El carácter estratégico de la comarca de Els Ports de Morella, en la confluencia de los antiguos Reinos de Valencia, Aragón y el principado de Cataluña, entre el litoral mediterráneo y el interior peninsular, así como su decidida e histórica vocación comercial y militar, ha determinado desde antiguo su papel como plaza fuerte, núcleo de parada, posta y fonda y, por consiguiente, como ciudad abierta a los flujos de visitantes, algunos «prototurísticos», como cuando la visitaron algunos viajeros románticos (Obiol, 1999 b).

2 Un buen ejemplo de este contexto es la filmación cinematográfica realizada en 1960 por el cineasta valenciano Emilio Poveda, titulada significativamente «El silencio de Morella».

3 La iniciativa de crear un Parador en Morella fue gestionada, en parte, por D. Manuel Milian, sobrino de Mossen Milián, hombre influyente en Barcelona, donde reside, y amigo de M. Fraga Iribarne, en esos años Ministro de Información y Turismo. Al final, la creación del Parador se frustra, si bien todavía hoy el Hotel-Palacio del Cardenal Ram se le conoce popularmente como «El Parador». Por otra parte, señalar que la política de Paradores de Turismo (Recuperación patrimonial + Turismo de gama alta) continua. En el año 2000 se ha abierto el último en la ciudad extremeña de Plasencia. 
cola) y la iniciativa de crear un Parador Nacional de Turismo en el palacio del Cardenal Ram, colocan ya definitivamente a Morella en la órbita del turismo contemporáneo (Obiol, 1999 a).

Mediados los años 1970 se abren nuevas sensibilidades hacia el turismo. La crisis de las bases del sistema económico-social (textil, ganadería/agricultura, comercio), la profundización de la emigración y un relativo desconcierto político, muy presente en las acciones urbanas (cierto descontrol urbanístico en la zona de extramuros y en l’Hostal Nou), generan una tímida respuesta de diversificación económica en la que el turismo, a pesar de los problemas, despunta ya como un sector clave de cara al futuro.

Los cambios sociopolíticos y económicos que se dan en España a principios de los años 80 se reflejan igualmente en la concepción urbanística y del territorio. Ante las negativas realidades citadas se toma conciencia de la necesidad de una respuesta inmediata capaz de frenar la alteración urbanístico-territorial y de reorientar la economía hacia una industria más diversificada y hacia un turismo más rentable y provechoso ${ }^{4}$.

Se entiende que el instrumento adecuado para conseguir estos objetivos es un Plan General de Ordenación Urbana (PGOU) que fije claros criterios de delimitación de suelo urbano e industrial, al tiempo que, a través de una adecuada legislación, preserve para su fomento turístico la singularidad socio-cultural y estética de Morella y su entorno.

Con los primeros estudios para la redacción del PGOU se confirman una serie de tendencias significativas sobre la evolución urbana de Morella en las décadas de los años 60, 70 y primeros 80 :

- Escasa transcendencia de las tareas de reforma y actualización de viviendas, algo sorprendente a tenor de la calidad de la edificación y de la escasez de suelo nuevo.

- La principal actividad se orienta por tanto a la nueva construcción, mayoritariamente dentro del recinto amurallado, aún a pesar del escaso suelo y el alto precio de los solares Se construye sobre todo en torno a su área central y Plaça de Colón, aprovechando cualquier espacio libre 5 .

- Se da un proceso curioso de mayor auge constructivo a medida que disminuyen los contingentes poblacionales, posiblemente debido a la presión de los naturales emigrados (turismo de retorno) y de residentes de fuera del núcleo urbano que ahora construyen intramuros (masovers). A pesar de que en los estudios tendentes a la realización del PGOU (1986) se señala que también influyó un cierto «turismo residencial», entendemos que, más allá de contados casos puntuales, este fenómeno fue prácticamente imperceptible

- Aparición, a partir de inicios de los años 70, del bloque de viviendas en pisos como novedad tipológica intramuros que rompe con la tradición constructiva, ocasionando un notable impacto visual en el entorno y en el conjunto urbano. Esta tipología, por fortuna, únicamente se circunscribe a escasos puntos concretos como el entorno de la iglesia de Sant Joan.

- Surgimiento de nuevas y variadas implantaciones edificatorias extramuros en l'Hostal Nou y en la cuesta de acceso por el Porta de Sant Mateu. Si bien las primeras edificaciones por su cota más baja apenas enturbian la visión panorámica de la

4 En este contexto se crea la Mancomunidad Turística del Maestrazgo en 1974, como organismo mixto e interprovincial susceptible de fomentar el turismo en la comarca del Bajo Aragón y en las de Els Ports de Morella y Maestrat, obligadas puertas de acceso para el turismo costero que aspiraba subir a las tierras de Teruel.

5 Supone el fin de los pequeños huertos urbanos tan peculiares y dotados de personalidad. 

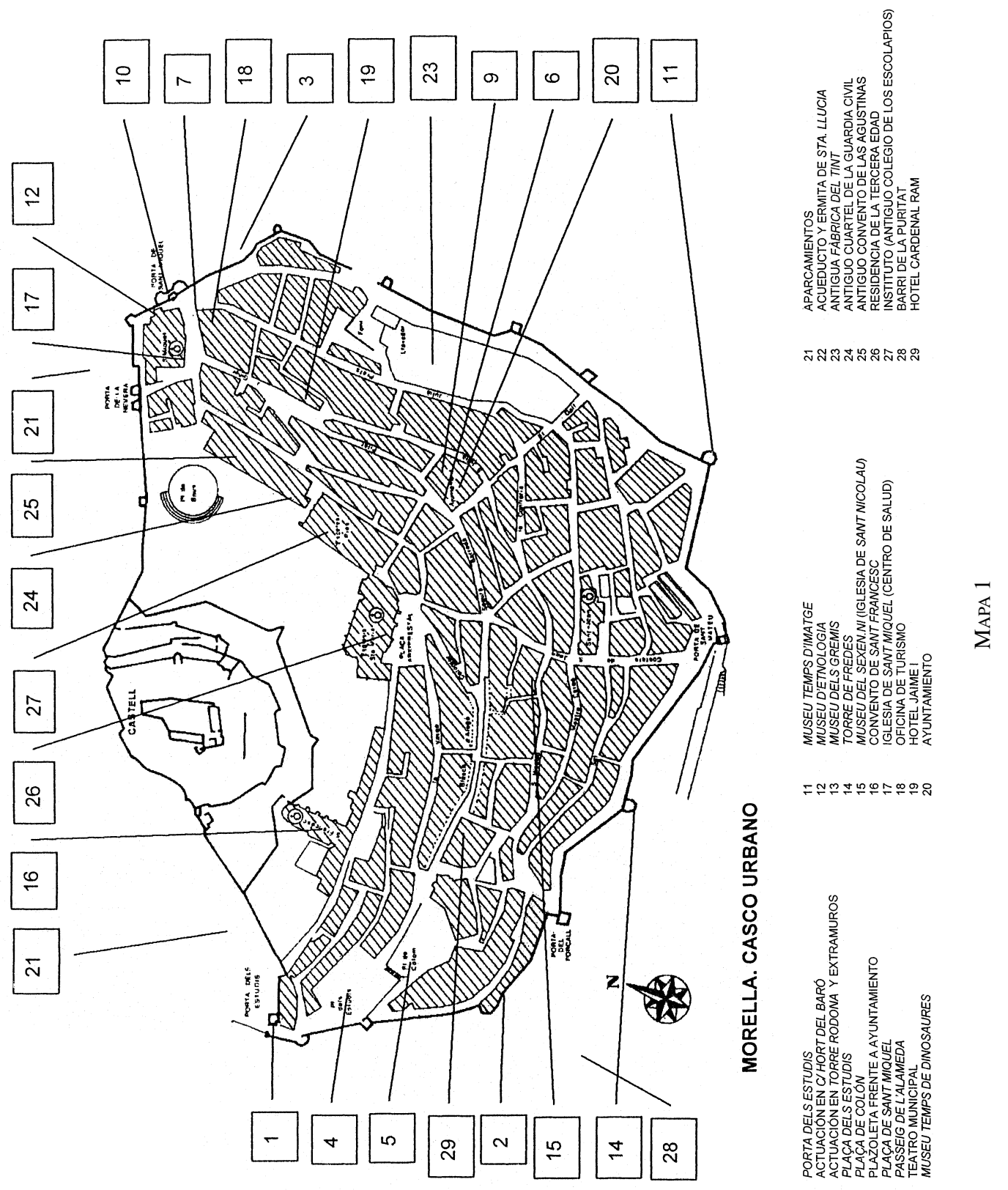

Investigaciones Geográficas, $n^{\circ} 26(2001)$ 
población, las segundas, a menudo, enmascaran la muralla y desvirtúan la imagen de Morella. Mención aparte merece el caso de las edificaciones residenciales surgidas en el camino hacia El Forcall en el denominado Barri de la Puritat, en donde, posiblemente sin buscarlo, se ha conseguido crear una serie de implantaciones que, prescindiendo de su calidad tipológica y estética, apenas entorpecen la percepción del conjunto histórico urbano.

\subsection{De la redacción y aprobación del P.G.O.U. (1984-1994) a la Agenda 21 Local (2000)}

Hacia 1984 se inicia la redacción de un pionero y novedoso Plan General de Ordenación Urbana (PGOU) que se pretende que sea el instrumento adecuado para conseguir la modernización de Morella, de acuerdo con unos parámetros que van a entender el turismo y el patrimonio como estrategias de actuación, globales y multidisciplinares, que optimizarán los recursos disponibles. El Plan fijará claros criterios de delimitación de suelo y preservará la singularidad y la autenticidad territorial de Morella y su entorno (PGOU, 1986).

Su redacción significó un intenso proceso de participación ciudadana que hizo nacer interesantes debates en torno a qué modelo de desarrollo socio-económico se quería para el municipio. Frente a opciones más conservadoras y agrarias, consiguió, no sin problemas, salir adelante la opción de diversificación socioeconómica basada en el fomento de un turismo cultural. A partir de su puesta en marcha, la ciudad empieza a experimentar una de las mayores transformaciones urbano-territoriales de su historia. El Plan supuso el verdadero instrumento de gestación de una nueva Morella ligada a la poliédrica actividad turística. Nueva etapa, y nueva vocación, que no sólo se circunscribía al municipio sino también a toda la comarca de Els Ports que, mirándose en el espejo de su capital, verá al turismo como el instrumento vital y posible (alternativo, sostenible, difuso, blando, complementario) capaz de propiciar un desarrollo desde abajo y atendiendo a criterios integrales.

En este periodo, la función turística irá paulatinamente reforzándose y aumentando la simbiosis entre ciudad y turismo. Se ha ido fomentando e interiorizando el discurso turístico que, coincidiendo con la fiesta de l'Anunci y sobre todo del Sexen.ni, (en el año 2000 se celebró el 51) marca objetivos y ciclos para 6 años. Desarrollo integrado y sostenible dirigido flexiblemente por el turismo y con claves de participación, calidad y profesionalización son premisas que una ciudad que quiere seguir siendo un lugar para vivir ha ido asimilando. Una ciudad histórica, Morella, que con apenas 3.000 habitantes, recibe en torno a los 500.000 visitantes/año (1998) una cifra similar a la que recibe, por ejemplo, la ciudad de Ávila o aproximadamente la mitad de los visitantes que recibe la ciudad de Salamanca, ambas Patrimonio Cultural de la Humanidad (Troitiño, 1999) galardón al que ahora aspira, justamente, Morella.

Como consecuencia de la nueva concepción del territorio que impulsa el PGOU, se inician una serie de actuaciones tendentes a paliar los graves déficits en infraestructuras y servicios, tanto generales como turísticos, que son simultáneos con el incremento, en progresión geométrica, de la celebración de acontecimientos, la afluencia de visitantes y la consiguiente rentabilidad de los primeros comercios orientados hacia el turismo ${ }^{6}$.

6 Los pioneros fueron los tradicionales: artesanía, productos agroalimentarios y gastronomía. Muchos de ellos se configuraron atendiendo al modelo taller-tienda.

La actitud de la administración local, impulsora de todo el proceso desde 1984, fue decisiva para que el turismo se concibiese como una actividad por, desde y para la población local. 
Las principales actuaciones territoriales y urbanísticas con decidida proyección turística y amparadas dentro del PGOU son las siguientes:

\subsubsection{Proyectos y planes de reforma y rehabilitación}

— En 1983 se inicia el primer Proyecto de Rehabilitación Urbana (1983-1987). En 1986 se redactan un Estudio Básico de Rehabilitación Integral, que constata el éxito de la iniciativa anterior, y paralelamente, un Estudio de la Imagen de la Ciudad de Morella.

- Otros documentos importantes han sido el Programa de Renovación Urbana 1 referido a la parte alta del centro histórico (aprobado por la Generalitat Valenciana en fecha de 18-V-1992), y la Propuesta de Declaración del Programa de Renovación Urbana 2 aprobada por el ayuntamiento de Morella posteriormente (14-I-1994).

- En la actualidad existe un Proyecto de Conservación y Saneamiento Integral de Morella, el cual está orientado a mitigar los déficits infraestructurales.

2.2.2. Esponjamientos intramuros con objetivos de abrir espacios y dedicarlos a equipamientos

— Derribo de casas junto a la Porta dels Estudis (Mapa 1). Potenciación, ampliación y embellecimiento de una de las «puerta de salida» de la ciudad.

- Derribo de varias casas en el denominado Hort del Baró. Creación de un pequeño jardín intramuros, con árboles, que descubre por dentro un importante lienzo y perspectiva de muralla.

- Creación de un pequeño jardín en las inmediaciones de la Torre Rodona y su ampliación y conexión (en proyecto) hasta la Porta y Torres de Sant Miquel.

\subsubsection{Reforma y nueva concepción de singulares espacios urbanos}

— Remodelación de la Plaça dels Estudis. Supuso su modernización, bien conseguida, a lo que contribuyó no poco una vanguardista escultura-reloj de sol.

- Remodelación de la Plaça de Colon. Se configura como una gran escalinata tendente a convertirse en mirador en la parte alta, y como transición hacia una pequeña glorieta en la parte baja. La conexión entre esta plaza y la anterior pensamos que podría mejorarse notablemente.

- Remodelación de la plazoleta existente frente al Ayuntamiento.

- Remodelación, con readoquinado, de la Plaça de Sant Miquel.

- Gran transformación del Passeig de l'Alameda concebido como el pulmón verde de la ciudad, área de descompresión urbana y turística, y como una circunvalación extramuros abierta al paseo, al disfrute natural y a la contemplación de la «espalda» de Morella.

El CISE (Centre Integrat de Serveis Econòmics), el Patronat de Turisme, la ASETMYCO (Asociación de Empresarios Turísticos de Morella y Comarca), las presentaciones de la ciudad en las principales ciudades de España, la Fira Ramadera, el continuo reciclaje y formación de los recursos humanos, el Curso y Festival Internacional de Música, los cursos universitarios de verano de la UJI y otras muchas iniciativas, son hechos que contribuyen a enriquecer el destino turístico de Morella.

7 Las «espaldas», extramuros, de la ciudad generan controversia entre los residentes a la hora de instalar allí los servicios y equipamientos. La falta de suelo intramuros, los deseos de la población de tener cerca de sus casas dichos servicios, la necesidad de mantener sin impactos la imagen turístico-patrimonial, y el posible aprovechamiento de economías de escala, son argumentos que se manejan habitualmente en el debate. ¿Debe ser sólo 
2.2.4. Conservación, restauración, rehabilitación y reestructuración ${ }^{8}$ de edificios

- Reforma del Teatro Municipal.

- Creación de una red de museos. Ante el objetivo último de crear un gran museo ${ }^{9}$ se ha optado por una política museística diversificada, descentralizada y temática utilizando las antiguas torres de la muralla como contenedores museísticos. Así:

- Museo Temps de Dinosaures instalado en las mismas Torres de Sant Miquel refuncionalizando estas (30.000 visitantes en 1999).

- Museo Temps d'Imatge instalado en la Torre Beneito. Potenciación (en proyecto) con nueva documentación gráfica, cartelística y cinematográfica.

- Creación de un Museu Etnològic frente a la casa de las torres de Sant Miquel (en proyecto). Creación del Museu dels Gremis (en proyecto).

- Creación en la Torre de Fredes de un centro de estudios que albergaría colecciones de monedas y el archivo de M. Milián, (en proyecto).

- Creación de una sala de Exposiciones en la antigua iglesia de Sant Nicolau. Está prevista en este recinto la instalación del Museu del Sexen.ni (en proyecto).

- Restauración de la iglesia de Sant Francesc y su conversión en espacio polivalente (por ejemplo ha albergado desde exposiciones y conciertos, hasta plenos de las Corts Valencianes).

— Reforma de la iglesia de Sant Miquel y su reconversión funcional en centro de salud. Fue una iniciativa pionera, vanguardista y, por consiguiente, polémica.

- Construcción de la Tourist Info frente a la puerta de acceso principal de la ciudad. Se concibió como centro de acogida de visitantes.

- Construcción de hoteles utilizando casas tradicionales preservando la imagen de fachada, pero agregando unidades integradas interiormente (Hotel Jaume I).

— Rehabilitación y Reestructuración del edificio del Ayuntamiento.

- Rehabilitación y Reestructuración de la Fàbrica de Giner. Esta fábrica, una antigua colonia textil del siglo XIX a imagen de las catalanas creadas en el río Llobregat, se convirtió en el emblema turístico de Morella. Sus objetivos, a pequeña escala, resumían los perseguidos para la ciudad y comarca (Obiol, E.-Canós, H. 1998):

- recuperar y dinamizar el patrimonio a través de nuevos usos polifuncionales y turísticos.

- crear un complejo integrado (hotel, restaurante, albergue, escuela de montaña, recintos deportivos, parque, jardín) y descentralizado de implantación turística (situado a $3 \mathrm{Km}$ al NW de la ciudad) fomentando el desarrollo de otros espacios (en este caso

una gran área verde?, ¿puede alternar puntualmente, como ahora, con equipamientos educativos y lúdicos?, ¿deben estos equipamientos localizarse, integrados y concentrados, en otras partes $y$ que no sean las inmediaciones de la ciudad (Fàbrica de Giner)?

8 En general, se puede decir que las instancias privadas han apostado, lógicamente, más por procesos de conservación y rehabilitación, mientras que las instituciones públicas se han decantado por procesos de restauración y reestructuración.

9 Nuestra propuesta sería la creación, no de un modelo misceláneo dentro de un gran contenedor, sino de un modelo «Museo de la Ciudad» que se centrase en aspectos como el proceso de construcción y evolución de la ciudad o de las relaciones entre medio ambiente natural y construido. 
la ribera del río Bergantes). Algunas de las numerosas instancias rehabilitadas se convirtieron también en oficinas de la administración.

- convertir el complejo en el buque insignia del desarrollo turístico de la ciudad y de la comarca.

\subsubsection{Infraestructuras y servidumbres viarias}

- Construcción de la variante de Morella (Cs-840).

- Construcción del acceso NE a la ciudad a partir de la N-23210

- Construcción de dos aparcamientos públicos, para automóviles y autobuses, integrados en el entorno.

\subsubsection{Mejora estética y paisajística general}

— Intraurbana: supresión y enmascaramiento de líneas y acometidas. Respeto al carácter, tipologías constructivas y materiales autóctonos en las nuevas construcciones y reformas. Creación de iluminación general y monumental adecuada. Se ha procedido a una uniformización, insuficiente, de la rotulación y de la cartelística.

- Extraurbana: respeto a las perspectivas visuales del conjunto y elementos monumentales.

— El castillo ha sido el gran olvidado en el proceso restauración del patrimonio aunque sigue funcionado como hito turístico. Al contrario de lo que ha sucedido en otros municipios del País Valenciano (Xàtiva, Sagunt, Peníscola, Villena) donde el castillo ha sido catalizador turístico, aquí su delicado estado de conservación y la diversidad de administraciones competentes son, hasta ahora y de un modo inexplicable, problemas desgraciadamente irresolubles para un Monumento Histórico-Artístico convertido en Bien de Interés Cultural (BIC) después de la ley 16/1985.

- Restauración e integración del acueducto medieval y de la cercana ermita de Santa Llúcia en la unidad turístico-urbana de la ciudad.

-El cinturón de muralla y las 14 torres han conocido procesos de conservación y restauración que todavía hoy continúan. Se ha habilitado un recorrido turístico que, desde distintas perspectivas y niveles, abarca todo el perímetro amurallado.

\subsection{Falta de suelo y gestión urbano-turística}

La naturaleza roqueda del asentamiento, sobre una muela ${ }^{11}$ con notables pendientes, el recinto amurallado, así como la densificación progresiva e histórica de la trama urbana, han ocasionado una importante falta de suelo intramuros, no así de casas, susceptible de albergar nuevas construcciones. Extramuros la situación no es muy distinta. Aquí el PGOU determina importantes restricciones en la construcción debido al necesario respeto a la ser-

10 Este nuevo vial tenía por objetivo evitar el deterioro al que estaban sometidos, por efecto de los agentes contaminantes, la Porta de Sant Mateu y l'Aqueducte. Dicha puerta era, por necesidad, la entrada obligada de cualquier vehículo para acceder a la ciudad; mientras que el acueducto era atravesado por la carretera que conducía al municipio de Xiva de Morella. Hoy los nuevos accesos, corrigen los problemas apuntados, permiten otra perspectiva panorámica de la ciudad, y encauzan el tráfico hacia el aparcamiento de l'Alameda.

11 El topónimo Morella, etimológicamente, significa muela pequeña (Molella). 
vidumbre de espacios y a las perspectivas visuales derivadas del carácter de Conjunto Histórico-Artístico de la ciudad.

Ante esta realidad podemos concluir la gran presión urbanística existente en la actualidad. Esta imperante necesidad de suelo, ha propiciado, por una parte, un programa de liberación de suelo infrautilizado y/o dedicado a actividades ya caducas para un nuevo uso como suelo residencial y, por otra, la creación de una acción planificada en forma de polígono industrial. En este contexto las principales actuaciones han sido:

- Derribo de la Fàbrica del Tint ${ }^{12}$.

- Reutilización del solar del antiguo Cuartel de la Guardia Civil.

- Reutilización del solar del antiguo convento de las Agustinas.

- Creación del polígono industrial Les Casetes, frente al núcleo de l’Hostal Nou y pegado a la N-232, con el objetivo de ubicar y reagrupar allí la totalidad de la actividad secundaria. Ésta manifiesta un índice de dispersión elevado con los costes paisajísticos que ello conlleva. El reto de trasladar los talleres y las naves que salpican el acceso a la ciudad por la Porta de Sant Mateu puede ser un objetivo a medio plazo.

La gestión urbana para salvaguardar este rico patrimonio territorial y su puesta en valor turístico, no por compleja, debe descuidarse. Así se deberán arbitrar medidas para:

- Compaginar la conservación y protección de los valores naturales y culturales con la actividad económica (Noguera, 1997).

- Definir estrategias, de revisión periódica y responsable, que ordenen la evolución urbana y de ocupación del territorio acabando con los crecimientos espontáneos e indefinidos.

- Proteger aquellos elementos del patrimonio que, sin tener notabilidad, merezcan su conservación por su interés histórico, artístico, estético y medioambiental.

- Apostar por la revalorización del patrimonio edilicio, monumental y cultural tanto en el núcleo urbano como en el ámbito rural. En ello deberá participar activamente la población local o del entorno con el objetivo de generar empleo y rentas.

- Apostar por la protección y saneamiento del parque de viviendas existente frente a la expansión y ocupación de más suelo. Algo similar debe plantearse con las necesidades para uso dotacional. Ambas propuestas, lógicamente, con la flexibilidad pertinente.

- Concebir la ciudad no sólo como una unidad formal en sí misma, sino también como un conjunto percibido desde el exterior. La imagen visual, su percepción externa debe ser igualmente cuidada, intentando evitar las afecciones negativas y asegurar la valiosa imagen unitaria.

- Conservar los característicos huertos y patios intramuros.

- Evitar la congestión y contaminación atmosférica, visual y acústica.

- Proteger, de una manera especial, el paisaje, esto es la superposición de elementos naturales y culturales a través de la intervención del hombre sobre el territorio. Pro-

12 En esta antigua fábrica la Generalitat Valenciana quería construir viviendas que solucionasen el grave déficit de suelo que arrastra Morella. Problemas entre administraciones de distinto signo político (una constante en los últimos años), una vez más, han frenado el proyecto. 
tección que debe afectar igual a suelos de potencialidad económica como también a los de potencialidad ecológica, estética o turística. Para ello se requerirá una clara delimitación de los usos del suelo y un sistema eficaz de control.

\section{Agenda 21 local, el reto del desarrollo turístico integrado}

\subsection{Sostenibilidad y turismo. Conceptos compatibles}

El informe Brundtland (1987), la Conferencia de Medio Ambiente y Desarrollo (Río de Janeiro, 1992), la Carta de Aalborg (1994), la Conferencia Mundial de Turismo Sostenible (Lanzarote, 1995), la XIX Asamblea General de la ONU (1997), y el V PACMA de la UE (1998), han sido foros recientes donde se han puesto de manifiesto que determinados ecosistemas, como el mediterráneo, además de poseer una gran riqueza ecológica, muestran una elevada fragilidad ambiental a determinadas presiones, en nuestro caso la turística.

En esas instancias fueron adquiriendo cartas de naturaleza los conceptos de «sostenibilidad» $\mathrm{y}$ «Agenda 21», ambos interrelacionados, que pronto fueron adaptados a la industria turística. La sosteniblidad, o sustentabilidad, aplicada al turismo, implica que su desarrollo deberá ser soportable ecológicamente, viable económicamente y equitativo desde una perspectiva ética y social para las comunidades locales, que además lo planificarán de una manera integrada y sin comprometer las necesidades de futuras generaciones (PACA, 2000).

La sostenibilidad, y su programa marco, la Agenda 21, se conciben pues como un Plan de Acción Ambiental para lograr el desarrollo sostenible desde el punto de vista social, económico y ambiental. Plan que debe estar presidido, de una manera decidida y voluntariosa, por principios de transparencia, participación, democracia, subsidiariedad y responsabilidad.

En esencia, para que un modelo de desarrollo pueda decirse sostenible, debe asegurar tanto la prosperidad socio-económica como la preservación de la identidad cultural, debe universalizar la conciencia de que el medio ambiente merece ser respetado y protegido, y debe salvaguardar efectivamente ese entorno mediante la formulación de marcos políticos realmente comprometidos con la consecución de los mencionados deberes.

La Agenda 21 se configura, de este modo, como un marco de interpretación de las normas ambientales, recomendándose en su capítulo 28 que corresponde a las iniciativas locales, desde la base, tomar decisiones para su implementación. El aforismo "pensar globalmente, actuar localmente» adquiere aquí pleno sentido y la Agenda 21 se convierte en Local al tratar de reducir, a gran escala, las tensiones y las fricciones que se generan entre la industria turística, los visitantes, el medio ambiente y las comunidades anfitrionas.

El turismo por su carácter poliédrico y transversal, y por utilizar el medio natural como soporte y recurso, es una actividad que debe estar estrechamente relacionada con los planteamientos medioambientales. La misma Comisión Europea así lo entiende ${ }^{13}$ :

«El turismo es un elemento muy importante en la vida económica y social de la UE, refleja las aspiraciones legítimas de las personas de disfrutar de otros lugares, conocer otras culturas y sacar provecho de actividades distintas o del descanso fuera de su casa y del trabajo.

13 Resolución 93/C 138/01 de 1-II-1993. Programa comunitario de política y actuación en materia de medio ambiente y desarrollo sostenible (D.O.C.E. núm C 138, 17-V-1993). 
Es también una fuente de ingresos importante para muchas regiones y ciudades de la UE, y puede contribuir de forma especial a la cohesión económica y social de las regiones periféricas.

El turismo es un ejemplo claro de la estrecha relación existente entre el desarrollo económico y el medio ambiente, con toda su secuela de beneficios, tensiones y posibles conflictos.

Si se planifican y controlan adecuadamente, el turismo, el desarrollo regional y la protección del medio ambiente podrán ir a la par. Si se respetan la naturaleza y el medio ambiente, sobre todo en las zonas costeras y de montaña, el turismo podrá llegar a ser beneficioso y duradero»

Como mínimo la relación del turismo con el medio ambiente se establece en tres direcciones interactuantes. Por una parte, se comporta como una actividad que puede producir variados impactos medioambientales de carácter negativo. Pero, por otra parte, es quizá la actividad económica que más se resiente de la depredación medioambiental. Finalmente, sin embargo, el sector presenta un gran potencial de sostenibilidad al ser relativamente menos agresivo para el entorno que otros sectores socio-económicos (Troitiño, 1998).

Debe quedar claro que el turismo sostenible no es sinónimo ni de turismo rural, ni de turismo de calidad, ni tan siquiera de turismo propiamente dicho. El turismo rural no lleva implícita la sostenibilidad, no es más respetuoso con el medio que otras manifestaciones turísticas, ni lleva aparejada por definición la calidad. Incluso «estrictu sensu», es menos turismo que otros porque sostenibilidad implica, eso sí, el concurso de otras actividades socioeconómicas.

Por consiguiente, la sostenibilidad es un proceso plural a medio plazo — planificado, flexible, dinámico y participativo-, que guiado en nuestro caso por el hilo conductor del turismo, debe entender Morella como un ecosistema cultural integrado. Este sistema está presidido en todo momento por la población (residentes y turistas), a la que se trata de servir, para lo que es menester tratar adecuadamente una serie de áreas temáticas claves (urbanismo, medio ambiente, calidad de vida, ecología, patrimonio cultural y economía y turismo) que son las que permitirán alcanzar ese desarrollo sostenible (Calvià, 1999).

\subsection{Medio Ambiente y Morella}

Morella a las puertas del siglo XXI se encuentra, como producto turístico, en que prácticamente ha cumplido la primera fase de su ciclo vital, esto es ha experimentado un importante incremento en el número de visitantes y ha empezado ya la segunda fase caracterizada por la prosperidad turística. Una fase ésta llena de riesgos porque la ciudad ni puede ni debe supeditarse al monocultivo del turismo y debe lograr que la dimensión turística, transversal a la estructura económica y social, se integre en el marco de una realidad urbana habitable y multifuncional.

El turismo, en esta segunda fase, es uno de los pilares principales de la economía y sociedad y produce múltiples efectos inducidos, dinamizadores y multiplicadores. Esta actividad ofrece nuevas oportunidades para la recuperación, reutilización y conservación del patrimonio aportando asimismo recursos para mejorar el paisaje urbano, la trama y las infraestructuras. Pero el turismo no es una actividad inofensiva y además del riesgo de la unifuncionalización, empiezan a aparecer estrangulamientos que pueden hipotecar el futuro de la ciudad (De la Calle-García, 1998). 
En ese tránsito hacia la segunda fase del ciclo vital efectivamente se producen cambios importantes. En la demanda cada vez más se apuesta por rebajar la proporción de excursionistas y aumentar los de turistas, y en la oferta empieza a observarse que el turismo no sólo aporta beneficios, que hay que seguir maximizando, sino también costes medioambientales, económicos y sociales que hay que minimizar. En suma, la función turística está constatando que, ante unos recursos territoriales turísticos limitados, la problemática inherente a la frecuentación está ocasionando amenazas y debilidades ambientales.

El diagnóstico ambiental turístico de esas problemáticas, algunas de las cuáles se tratarán después individualmente, podrían esquematizarse para Morella en:

-Deterioro del patrimonio edificado.

- Contaminación atmosférica.

- Degradación del suelo y de los ecosistemas.

- Agotamiento de recursos naturales.

- Incremento de la generación de residuos.

- Carencia de servicios adecuados.

-Deterioro e insuficiencia de infraestructuras.

—Problemas con la capacidad de acogida.

Precisamente la capacidad de carga es un concepto clave para prevenir los impactos negativos de la sobrefrecuentación. El incremento del flujo de visitantes produce una serie de desbordamientos que hay que corregir. Morella empieza a tener problemas en el concepto de capacidad de carga física en determinados momentos y lugares de la ciudad, si bien es cierto que el límite de tolerancia económico y social goza de buena salud y no se ha superado.

Ante esos problemas ambientales, Morella a lo largo de los últimos años ha tratado de adecuar su política al nuevo escenario turístico que se vislumbra. La ciudad debe persuadirse de que un turismo bien gestionado es un buen aliado del medio ambiente, que una industria turística exitosa necesita un medio ambiente de alta calidad (PIRCT,1996) y que el desarrollo turístico sostenible es realmente la única fórmula de futuro que puede promoverse. De ahí la apuesta que ahora se hace por el plan de acción de la Agenda 21.

\subsubsection{Cubierta forestal}

El municipio de Morella, el más extenso del País Valenciano por detrás de Requena, Ayora y Orihuela, significa el $7 \%$ de la superficie provincial y el $2 \%$ de la comunidad autónoma. En consecuencia, tanto cuantitativa como cualitativamente presenta una riquísima biodiversidad que debe gestionarse correctamente. Un $77 \%$ de su superficie es terreno forestal y a la que se debe una optimización de recursos para que pueda seguir realizando su función principal y poder acoger otras complementarias relacionadas con el turismo. Y mucho más desde 1982 cuando esta masa boscosa ha estado sometida a una muy importante contaminación en forma de lluvia ácida que supuso en la comarca la tala de 13.000 pinos y que afectó en la comarca de Els Ports y aledaños a 220.000 ha (PACA, 2000).

Como supuesto, se baraja que la cercana central térmica de Andorra (Teruel) es la responsable de éste importante atentado ecológico. Los daños ocasionados, cuyos claros efectos se han podido ver en los bosques, pero no así de momento en otros recursos (ecosistemas, agua, arquitectura o paisaje), han creado una serie de desasosiegos e incóg- 
nitas que, a pesar de las contraprestaciones en dinero de la empresa (Endesa), no han podido despejarse. Precisamente el organismo que gestionó tales ayudas de Endesa, la Fundació Els Ports-El Maestrat, dedicó buena parte de su presupuesto a acciones de turismo alternativo ${ }^{14}$.

Así las cosas, agravadas por un medio rural desarticulado, prácticamente despoblado de masovers, y relativamente inactivo (sólo la ganadería sigue siendo relativamente importante), la realidad impone un nuevo tratamiento del espacio rural. Ante la pujanza turística del municipio se aconsejaría la conveniencia de regular normativamente los parajes más valiosos del término.

La apuesta necesaria sería la declaración de Els Ports de Morella como Parque Natural. Esta medida permitiría reordenar los usos del suelo y la gestión forestal, así como un tratamiento adecuado de la fauna y flora de la comarca, afectada por problemas de pérdida de razas autóctonas, esquilmación de los bosques o erosión del suelo. Además, normativamente, se compatibilizaría desarrollo y medio ambiente.

Los PORN y PRUG resultantes procederían a un inventario exhaustivo de los recursos territoriales turísticos para posteriormente delimitar una serie de unidades de paisaje que, protegidas, deberían ser puestas en valor integral y turístico. En el peor de los casos, y aunque se desaconseja, la figura del Paraje Natural Municipal, siempre está ahí como recoge la Ley valenciana 11/94 y la española 40-41/1997. Se sabe el peso que comporta tal declaración, pero tal vez una acción piloto (entre Vallivana y Moixacre, Els Fusters) sería una buena punta de lanza para hilvanar una vía hacia un tanto desasistido turismo ecológico que debe tomar como base estratégica la declaración de la comarca de Els Ports de Morella como Parque Natural ${ }^{15}$.

La oferta medioambiental debería completarse, mientras se gestiona la declaración de Parque, con la instalación de Centros de Interpretación (C.I.). Hay proyectos de crear un C.I. de icnitas en la Vallivana, y otro C.I.-Museo del mundo rural en Morella la Vella. También el proyecto de Ecomuseo de Els Ports-Maestrat debería retomarse potenciándolo.

\subsubsection{Las Aguas}

El volumen anual de aguas potables suministradas alcanza los $297.039 \mathrm{~m}^{3}$ (1995) para una población residente de 2.719 habitantes (1998) y 0,5 millones de visitantes/año (1998). Existen tres pozos que poco menos aseguran el simple suministro. Las restricciones de agua, una constante en la comarca, ante el crecimiento de la demanda pueden ser una triste realidad si no se pone en funcionamiento de modo urgente el nuevo pozo del Mas del Noto.

14 Entre otras cabe destacar las contempladas bajo el proyecto: Els Ports-Maestrat, patrimoni de futur. Dentro de él se diseñó un interesante proyecto de Ecomuseo (1997-1998) con centros de atención preferente en la ganadería y en los masos.

También un conjunto de rutas e itinerarios a través de las series: Arbres Monumentals, Camins i Paisatges, con objetivos de educación medioambiental, ecoturismo y conservación de la biodiversidad.

15 Así lo ha entendido, por ejemplo, la Generalitat de Catalunya, al declarar como Parque Natural (Espacio Natural Protegido) la vecina comarca de Els Ports de Besseit.

Tal declaración para Els Ports de Morella implicaría una gestión forestal y cinegética más adecuada, también de los recursos mineros (graveras en ramblas), de la flora (por ejemplo el endemismo del clavel de la Balma) y de la fauna (buitre, águila perdicera, alimoche). Por otra parte, permitiría estudiar y corregir los importantes impactos que las infraestructuras viarias (carreteras) imprimen a las realmente espectaculares vías pecuarias, o a otro nivel las repercusiones sobre las singulares construcciones de piedra en seco (se ha pedido para ellas la declaración de Patrimonio de la Humanidad) o sobre las pinturas rupestres. 
Los problemas inherentes a las aguas mediterráneas, sobreexplotación y contaminación, en acuíferos y en superficie (Pérez de las Heras,1999) están presentes, por lo cual Morella debe trabajar para que el turismo, altamente dependiente del agua (potable, en cantidad y calidad), no encuentre aquí estrangulamientos para su desarrollo. La ampliación de la depuradora es perentoria.

Con 24 cauces menores (barrancos), 11 fuentes, otros tantos molinos y batanes, un término municipal que drena mayoritariamente hacia la cuenca del Ebro pero también hacia la cuenca meridional del Júcar, y un río relativamente importante, el Bergantes, la escorrentía superficial siempre ha estado presente en Morella.

Dos propuestas en este sentido. Tal vez, en el entramado urbano, las fuentes ornamentales, un valor añadido en una ciudad turística, cabría hacerlas más presentes. Por otra parte, quizá cabría recuperar algún tramo de margen del Bergantes ${ }^{16}$, cercano a la población, y que pudiese servir de cornisa, área verde o mirador de la ciudad. Tal vez al sur de la ciudad, el Molí y el Pont Trencat y sus alrededores podrían ser una buena zona, con la circunstancia añadida de que además permitiría la restauración de dicho puente.

La reciente propuesta de construir un balneario en la Fàbrica de Giner (Mapa 2) nos parece, por el momento, bastante aventurada a tenor de las circunstancias de sequía prolongada que vive la comarca.

\subsubsection{Aire}

La contaminación ambiental del aire es un problema grave que afecta a toda la comarca, si bien es cierto que la ciudad, por su emplazamiento, queda fuera del desagradable olor ocasionado por la omnipresente ganadería estabulada principalmente porcina.

Por su carácter disperso, y por la carencia de sistemas adecuados de eliminación y tratamiento de residuos, las granjas son una fuente de contaminación difusa e importante. Sus residuos orgánicos tienen un elevado contenido de nitrógeno lo que les convierte en desechos de alta potencialidad contaminante.

Las soluciones pasan bien por una acumulación individual y su posterior aplicación agronómica (tal y como están las explotaciones agrarias es una entelequia), por crear polígonos de granjas (otra utopía) o por vertederos controlados y plantas de depuración de cuyos tratamientos puedan obtenerse subproductos (biogas, compost, cogeneración) que incluso podrían reaprovecharse vía energía. Existen algunas balsas de reagrupamiento pero falta lo más importante: la planta de depuración y reciclaje. Está prevista y poco más.

Los generadores eólicos, por su trascendencia paisajística y ecológica, son un tema muy preocupante en la ciudad. Se impone una racionalización en la ubicación de éstos y, por supuesto, que todos ellos respeten en su instalación el campo visual, como mínimo, desde Morella.

16 Un estudio reciente de la oficina gestora del Programa LIFE proyecta crear un espacio ecoturístico verde siguiendo el cauce del río Bergantes desde Morella hasta Sorita $(36 \mathrm{Km})$. Entre sus alternativas figuran: la creación de un paseo fluvial, la instalación de casetas de observación y miradores en el valle del Bergantes, la disposición de centros de acogida, la adecuación de aparcamientos y paneles informativos y la puesta en marcha de rutas verdes y de un parque eco-fluvial.

Este proyecto se inscribe en otro mayor, todavía en sus primeros pasos, conocido como la «Ruta dels Tres Reis». Este pretende, sobre la iniciativa de las ciudades de Morella, Alcañiz y Tortosa, construir un espacio de colaboración, intercambio de experiencias y aprovechamientos de sinergias, que puede beneficiar a las comarcas respectivas. Además, el proyecto que implica a 3 Comunidades Autónomas, anteriormente pertenecientes a la Corona de Aragón, puede generar impulsos turísticos complementarios. 


\subsubsection{Residuos Sólidos Urbanos (R.S.U.)}

Morella produce $18.869 \mathrm{Tm}$ de residuos sólidos/año, con una diferencia importante, $75 \%$ de incremento, entre el invierno $(4.560 \mathrm{Kg} /$ día $)$ y el turístico verano $(7.980 \mathrm{Kg} /$ día $)$. Existe un vertedero municipal, relativamente incontrolado, poco más que un talud sobre barranco, y en el que no existen tratamientos de humos, olores y dioxinas. La creación de un vertedero controlado en Vilafranca impide, según alguna administración, la construcción de uno nuevo en Morella que sí está previsto.

Por lo demás existe recogida selectiva de vidrio, papel-cartón, pilas, aceite vehículos, y recogida diaria de basuras por parte del ayuntamiento que ahora está estudiando su privatización. En estudio también está un vertedero para residuos inertes y para neumáticos.

La incierta situación del Plan Integral de Residuos del País Valenciano y la inexistencia de un Plan Estratégico para la provincia de Castellón de la Plana, complican una situación ya de por sí un tanto espinosa.

\subsubsection{Calidad Urbana}

Morella es una ciudad que vive dentro de la muralla y con calles estrechas, concéntricas y radiales siguiendo las curvas de nivel. Por tanto su accesibilidad rodada se realiza de E-W y es prácticamente imposible hacerla transversalmente, esto es N-S, donde las calles son tramos más o menos interrumpidos de cuestas con o sin escaleras.

Como para otras urbes semejantes, el automóvil es un lastre (Pérez de las Heras, 1999), un cuerpo extraño que consume mucho espacio, un bien realmente escaso, disputándoselo además a los peatones. Sin embargo, es cierto, facilita, la accesibilidad a determinados puntos centrales que, coinciden además con los grandes hitos turísticos a visitar.

El tema del tráfico todavía se complica más cuando la calle central, es la única vía apropiada para la circulación automovilística y concentra la principal oferta de servicios ordinarios y turísticos.

Las acciones emprendidas han sido parciales, blandas y disuasorias, aplicándose según los tiempos y los espacios, y procurando compatibilizar necesidades y deseos de habitantes y turistas. Se ha procedido a una peatonalización parcial, restringiéndose el tránsito en periodos de alta frecuentación de visitantes, prohibiéndose el estacionamiento en periodos largos en el centro de la ciudad y, por supuesto el aparcamiento, para lo que se han creado dos zonas de aparcamiento cercanos a las puertas e integrados en el entorno. En fin de semana y en periodos punta la calle central se corta al tráfico rodado.

Con todo, callejear en Morella es todavía una asignatura pendiente. Es cierto que topográficamente no invita, pero no lo es más que turísticamente es un recurso notable que debe promocionarse. Una creación de rutas urbanas y periurbanas ramificadas permitiría callejear y evitar masificaciones y sobrecargas indeseables en los lugares centrales. Para ello, una señalización propia, adecuada, sobria, concisa y homogénea, no demasiado vistosa, que ni estorbe ni distraiga, sería conveniente.

Asimismo se han realizado otras acciones de mejora de la calidad urbana: cierta adecuación de aceras para ganar confort y seguridad; readoquinados; rehabilitación de viviendas; construcción de otras nuevas siguiendo criterios bioclimáticos; corrección de la contaminación lumínica a partir de lámparas de vapor de sodio y reguladoras del flujo de luz (en proyecto). 


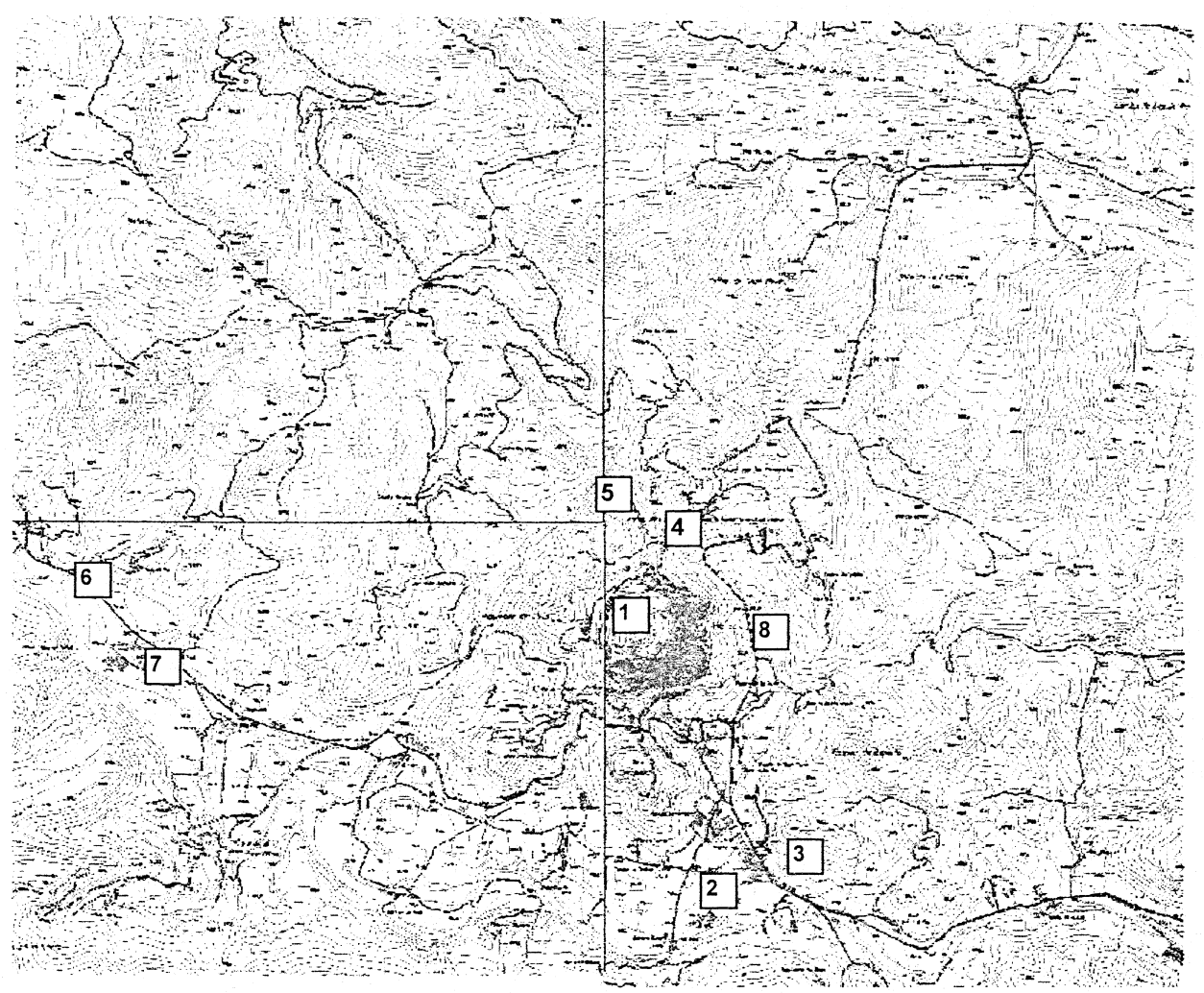

MORELLA. PLANO DE ACTUACIONES DE EXTRAMUROS

\author{
MORELLA CASCO URBANO \\ HOSTAL NOU \\ POLIGONO INDUSTRIAL LES CASETES \\ ACUEDUCTO \\ INCINERADORA DE BASURAS \\ RIU BERGANTES \\ FÄBRICA DE GINER \\ CARRETERA DE CIRCUNVALACION
}

MAPA 2

Con todo, el objetivo es alcanzar el equilibrio entre las necesidades, por una parte, de los ciudadanos que habitan en la ciudad y, por otra, de los turistas. Ambos componentes que generan flujos y tráficos distintos, deben estudiarse, ordenarse y hacerse compatibles en beneficio de la ciudad.

\title{
4. Conclusiones
}

El excelente acervo de patrimonio territorial de Morella y su excentricidad geográfica, han permitido, junto con una buena gestión pública y privada, construir, mantener y revalorizar una ciudad que hoy es un consolidado destino turístico de interior caracterizado por 
su perfil de turismo cultural. Su número de visitantes sigue creciendo situándose en 0,5 millones/año (1998), una cifra similar a la de algunas ciudades ya declaradas Patrimonio de la Humanidad.

Un amplio conjunto de acciones territoriales de mejora y adecuación en el ámbito urbano (infraestructuras, equipamientos, trama urbana, procesos de restauración patrimonial, esponjamientos), con objetivos de modernizar la ciudad y de ponerla en valor cultural, han adecuado la forma y han transformado el fondo y la imagen percibida de la ciudad, desde dentro y desde fuera, que hoy no se entiende sin la referencia turística.

Con ciertos estrangulamientos temporales (tráfico, residuos, recursos naturales escasos y deteriorados, capacidades de carga en el límite) derivados de la masificación turística, si se quiere periódica, y de la homogeneización del producto, a pesar de la peculiaridad geográfica, el municipio debe apostar por parámetros de sostenibilidad que intenten corregir dichos déficits. Cuatro grandes vías, en el marco de la Agenda 21 local, podrían encauzar el futuro:

- La excelencia y la calidad en la prestación de los servicios turísticos de la marca «Morella».

- La diversificación, complementaria, de escenarios turísticos.

- La imagen de singularidad, compatible con la máxima innovación.

- La gestión profesional y sostenible, sobre todo en la oferta, transmitiéndola asimismo a la demanda.

Vías que, en su lectura territorial y a modo de macropropuestas podrían resumirse en:

- Conseguir la creación de un Parador Nacional de Turismo, con la consiguiente vitola de alta calidad que conlleva.

- Seguir trabajando para la creación del Parque Natural de Els Ports de Morella. Mientras, ir incorporando al nicho de mercado principal, el turismo urbano y cultural, una dimensión hasta ahora minusvalorada o tratada sólo como pretexto: el espacio rural, verde, biodiverso y con una inmensa potencialidad en cantidad y calidad, es decir, su patrimonio natural.

- Seguir profundizando en la imagen de marca «Morella» como sinónimo de ciudad del arte, sin perder otras características: moderna, precursora, ligada al diseño y referente de vanguardia turística. Deberían hacerse esfuerzos para integrarla dentro de los circuitos de ciudades históricas y monumentales de España.

- Trabajar para que toda la oferta turística de Morella pueda adaptarse, en el plazo del año 2010, a los requisitos auspiciados por la Agenda 21 al tiempo que la demanda sea consciente de ello y convierta al destino como referente de turismo sostenible.

El instrumento adecuado para hacer realidad estas macropropuestas podría ser la consecución de un Plan de Dinamización y Excelencia Turística.

\section{Bibliografía}

CRUZ OROZCO, J., LÁZARO, M.J. I CANÓS BELTRÁN, H. (1996): Estudi-diagnòstic del Sector Turístic a l'àmbit d'actuació de la 'Fundació Els Ports i el Maestrat. Fundació Mediambiental, Valencia. 
DE LA CALLE VAQUERO, M. - GARCÍA HERNÁNDEZ, M. (1998): «Ciudades históricas:patrimonio cultural y recurso turístico». Ería, n 47, pp. 249-267. Universidad de Oviedo.

GAMUNDÍ CARCELLER, S.-SANGÜESA ORTÍ, C. (1997). Morella. Guía del antiguo término. Ajuntament de Morella.

LÓPEZ OLIVARES, D. - CANÓS BELTRÁN, H., (EN PRENSA): «La dinàmica generada pel turisme d'interior obliga a l'Ordenació i Planificació amb carácter sostingut i sostenible dels recursos existents a les àrees rurals», Actes de la XL Assemblea Intercomarcal d'Estudiosos, Morella 1996.

LOPEZ OLIVARES, D. - CANÓS BELTRÁN, H., (EN PRENSA): «Acercamiento a la promoción y gestión del turismo cultural en la comarca castellonense de Els Ports de Morella-Tinença de Benifassà», Actas de las VI Jornadas de Geografía del Turismo. Las Palmas de Gran Canaria 1998.

LÓPEZ OLIVARES D. Y CANÓS BELTRÁN, H., (1999): «La señalización turística en las comarcas interiores del norte castellonense». Actas de las VI Jornadas de Estudios del Maestrazgo, Boletín Centro de Estudios del Maestrazgo, nº 62. Benicarló.

MINISTERIO DE ECONOMÍA Y HACIENDA (1999): España. Un turismo sostenible. Madrid $95 \mathrm{p}$.

NOGUERA TUR, J. (1997). Desarrollo integrado y ordenación del territorio: diagnóstico para els Ports de Morella y el Alt Maestrat. EIC, Valencia, $191 \mathrm{p}$.

OBIOL MENERO, E. M. (1999 a). «El Maestrazgo-Morella como ejemplo de desarrollo de turismo rural». en La Actividad Turística Española en 1998. Asociación Española Expertos Científicos en Turismo. (AECIT), pp. 535-550. Madrid.

OBIOL MENERO, E.M. - CANÓS BELTRÁN, H. (1998): «Turismo rural e iniciativa Leader. La experiencia del País Valenciano». IX Coloquio Nacional de Geografía Rural. AGE- Universidad del País Vasco, pp. 167-177. Vitoria.

OBIOL MENERO, E.M. (1999 b): «Las Guías de Valencia (1840-1930). Notas para una análisis turístico». Cuadernos de Geografía, n 65-66 pp. 255-265, Departament de Geografia, Universitat de València.

PÉREZ DE LAS HERAS, M. (1999): «Ciudades y medio ambiente», Ecosistemas, año VIII, no 4 pp. 29-57. Madrid.

PÉREZ DE LAS HERAS, M. (1999): «Turismo y medio ambiente», Ecosistemas, año VIII, no 2, pp. 32-59 Madrid.

PLAN DE ACCIÓN. Calvià. Agenda Local 21. La Sostenibilidad de un municipio turístico. (1999). Ajuntament de Calvià. 111p.

PLAN GENERAL DE ORDENACIÓN URBANA DE MORELLA (PGOU) (1986). COPUT, Generalitat Valenciana. València.

PLAN INTEGRAL DE REACTIVACIÓN Y CALIDAD TURÍSTICA DE MORELLA (PIRCT) (1996). Ajuntament de Morella.

PREDIAGNÓSTICO Y AUDITORÍA DE CALIDAD AMBIENTAL DE MORELLA (PACA) (2000). Ajuntament de Morella.

TROITIÑO VINUESA, M.A. (1998). «Turismo y desarrollo sostenible en ciudades históricas», Ería, n 47, pp. 201-229. Universidad de Oviedo.

TROITIÑNO VINUESA, M.A. (1999). «Experiencias de Desarrollo Sostenible en Ciudades Históricas». Curso de Gestión y Planificación del turismo sostenible: Principios y Prácticas. UIMP, Alicante. Actas, t. III, pp. 1-22. 